\title{
A Comparison of Office Blood Pressure, Telemedical Home Blood Pressure and Ambulatory Blood Pressure Monitoring
}

\author{
Nikolai Hoffmann-Petersen* and Erling B. Pedersen
}

\author{
University Clinic of Nephrology and Hypertension, Departments of Medical Research and Medicine, Holstebro Hospital \\ and Aarhus University, Denmark
}

\begin{abstract}
Background: Telemonitoring of home blood pressure (HBP) is a new advance in blood pressure monitoring. The aim of this study was to compare office blood pressure (OBP) and telemedical home blood pressure with daytime ambulatory blood pressure (ABP). Methods: One hundred and two patients were recruited consecutively from our Renal Outpatients' Clinic. Office blood pressure was measured three times with the HBP equipment (A\&D UA-767Plus BT). Telemonitoring of HBP was done for four consecutive days with three measurements three times daily followed by ABP (A\&D TM-2430) on the next day. All patients received a questionnaire regarding acceptance of the equipment. $\underline{\text { Results: }}$ OBP was a significantly higher than daytime ABP (systolic/diastolic, 3.3/3.8 $\mathrm{mmHg}$ ). HBP was significantly lower than daytime ABP (systolic/diastolic, $-4.6 /-1.6 \mathrm{mmHg}$ ). The strongest correlations were seen between all HBP readings day 2-4 and daytime ABP (systolic, $r=0.69, \mathrm{p}<0.001$; diastolic, $\mathrm{r}=0.61, \mathrm{p}<0.001$ ). There were no significant differences between the different HBP schedules, i.e. 3 measurements twice daily for 3 days and 3 measurements three times daily for 4 days. Patients were content with and accepted the HBP measuring device. Conclusion: The telemedical HBP was lower than daytime ABP. The observed difference could possible be due to less pain and more relaxation during HBP measurements or a systematic difference in the algoritms between the blood pressure measuring devices. HBP measurement during three days was as good as measurement during 4 days.. The equipment was well accepted among patients.
\end{abstract}

Keywords: Home blood pressure measurements, hypertension, telemedicine, telemedical home blood pressure, telemonitoring, TM-2430 and UA-767PlusBT.

\section{INTRODUCTION}

Hypertension is a well-established risk factor for cardiovascular disease and one of the leading causes of death worldwide [1]. There are currently three options for the assessment of blood pressure - office blood pressure measurements (OBP), 24-hours ambulatory blood pressure measurements (ABP) and home blood pressure measurements (HBP). Measuring blood pressure at home shares some of the advantages of ambulatory blood pressure measurements, excluding the white coat effect, providing better reproducibility, and better prediction of organ damage and risk of cardiovascular events [2]. Isolated office hypertension ("white coat hypertension") may be present in about one third of individuals in whom hypertension is diagnosed [3]. Isolated office hypertension carries a lower cardiovascular risk than raised office and ambulatory blood pressure (sustained hypertension) [4-6]. The reverse phenomenon of "white coat hypertension" is called isolated ambulatory hypertension ("masked hypertension"). The prevalence of isolated ambulatory hypertension is about $13 \%$ [2]. Masked hypertension increases the cardiovascular risk nearly as much as sustained hypertension [3].

HBP is superior to OBP and comparable to ABP in predicting cardiac and renal damage in hypertension. HBP

*Address correspondence to this author at the Departments of Medical Research and Medicine, Holstebro Hospital, 7500 Holstebro, Denmark; Tel: +45 78436584; Fax: + 45 78436582;

E-mail: nikolai@hoffmann-petersen.dk correlates better with target organ damage and cardiovascular mortality than OBP [7-9]. Use of HBP is associated with a better compliance to treatment [10] and better control of hypertension $[9,11,12]$. HBP may also overcome therapeutic inertia [13]. Home blood pressure telemonitoring systems share most advantages of the traditional HBP, while improving the quality of data reporting and facilitating their interpretation. In HBP without telemedical transmission or electronic storage of data, patients may be tempted to report lower BP values than obtained or to report values which have not been measured [14-17].

The aim of this study was to test usability of a telemedical HBP monitoring equipment and to compare OBP and telemedical HBP with daytime ABP.

\section{MATERIALS AND METHODS}

\section{Patients}

\section{Recruitment}

Patients were consecutively recruited from the Renal Outpatients' Clinic, Holstebro Hospital.

\section{Inclusion and Exclusion Criteria}

Inclusion criteria: Patients in whom ABP was planned as part of the clinical monitoring. Both men and women. Age above 18 years. Exclusion criteria: Lack of mental or physical capacity to monitor blood pressure at home. Atrial fibrillation. Unwillingness to participate. Withdrawal criteria: 
Changes in medication during the periods where HBP and ABP were measured or between the two periods. More than $2 \times 3$ missing HBP measurements during the study. An ABP with less than 30 blood pressure measurements. Development of exclusion criteria.

\section{Number of Subjects}

It was calculated that 95 patients should be included in the study to detect a difference between daytime ABP and telemedical HBP of $1.5 \mathrm{~mm} \mathrm{Hg}$ with a $\mathrm{SD}$ of $4.5 \mathrm{mmHg}$ at a significance level of $5 \%$ with a power of $90 \%$.

\section{Experimental Procedures}

Participants were given instructions (written and orally) on handling the telemedical HBP equipment. Office blood pressure was measured in the clinic. The patients had the HBP equipment at home for 4 days. On the fifth day they returned the HBP equipment and underwent a 24-h ABP using the same arm as in the OBP and the HBP.

\section{Blood Pressure Measurements}

\section{Office Blood Pressure}

OBP was measured in sitting position after 10 minutes of rest with the arm supported, the cuff at heart level and cuff size based on upper arm measurements according to the ESH guidelines [2].

Initially two measurements were made in order to accustom the patients to the procedure. Next three measurements were recorded with an interval of one minute. Office blood pressure was calculated as a mean of the last three measurements. The equipment used for the office blood pressure measurement was the same as for the home blood pressure measurement.

\section{Telemedical Home Blood Pressure}

Telemedical HBP was measured using a telecommunication system consisting of a validated, semiautomatic oscillometric BP measuring device, UA-767PlusBT (A\&D Company Limited, Tokyo, Japan) and a telemedical monitor (Tunstall Healthcare RTX 3371). The patients were instructed to do three blood pressure measurements in the morning before going to work (between 6 and 8 a.m.), three blood pressure measurements before dinner (between 5 and 7 p.m.) and three blood pressure measurements before bedtime (between 9 and 11 p.m.) in the sitting position after $10 \mathrm{~min}$ utes of rest. These measurements were done on four consecutive days. Via Bluetooth connections, the blood pressure measurements were sent from the device to the telemedical monitor. Interaction with the patient was done via a display on the monitor, via control of the measurement unit, and by using a loudspeaker with instructions.

The telemedical monitor exchanged data with the server system over the GPRS wireless network (mobil phone data network) after each session of three measurements.

\section{Ambulatory Blood Pressure}

24-h ABP was measured using a TM-2430 (A\&D Company Limited, Tokyo, Japan) just after completion of the 4 days of HBP. The TM-2430 is a clinically validated, oscil- lometric and fully automated ambulatory blood pressure measuring devices. The patients' blood pressure was measured at 15-minutes interval between 7.00 a.m. and 11.00 p.m. and 30-minutes intervals between 11.00 p.m. and 7.00 a.m. Participants were instructed to maintain their usual daily activities but to keep their forearm quiet and extended during measurements. Daytime ABP was calculated according to each patient's diurnal cycle.

\section{Questionnaire}

All patients received a questionnaire to obtain an impression of, acceptance of the device along with the instructions to the telemedical HBP equipment. They returned the fulfilled questionnaire on the fifth day together with the telemedical HBP equipment. The questionnaire comprised the following 9 questions:

1) Were there any problems in turning on the monitor?

2) Did you read the written operating instructions?

3) Was it easy to get clear signal on the monitor?

4) How was the blood pressure device to operate?

5) How was monitor to operate?

6) Did you miss any functionality of the monitor or did anything about the monitor bother you?

7) How was it to make three blood pressure measurements three times a day?

8) What did you think about the communication with the monitor?

9) Did the monitor and the blood pressure device fulfil your expectations?

\section{Effect Variables}

The primary effect variable was the difference between daytime ABP and telemedical HBP. Secondary effect variables were differences between OBP on one hand, HBP day 2-3 (three readings twice a day) and HBP day 2-4 (all readings) on the other.

\section{Statistics}

The statistical analyses were performed using the IBM SPSS Statistics (version 20). Student's paired t-tests were applied for comparison of mean values. Bland-Altman plots were constructed for further evaluation of the agreement of mean values. In these plots, limits of agreement were derived from the standard deviations of the mean difference between the measurements [18]. Correlation analyses were done using Person's test. All results are given as means \pm standard deviation. All data were normally distributed. $\mathrm{P}<0.05$ was the limit of statistical significance.

\section{RESULTS}

\section{Demographics}

During the recruitment period of six month 113 patients were included in the study. Eleven were excluded: One dropped out because of a very high blood pressure and the need of extra medication, one due to side effects of medica- 
tion, two had not an ABP performed as planned, and data from seven patients were rejected because of too few HBP measurements. Thus, data were analysed from 102 individuals (36 women and 66 men) with a mean age 55 years (range 17-81).

\section{Blood Pressure Measurements}

Table 1 shows mean OBP, daytime ABP, HBP each measuring day, HBP of day 2-3 (readings morning and evening), and HBP of day 2-4 (all readings). There was a gradual decline from OBP to ABP and further to HBP. Apart from day 1, systolic HBP was significantly lower than ABP. A significant decline in systolic HBP was seen from day 1 to day 2 ( $p=0.001)$, whereas the change in diastolic blood pressure was not significant. The day to day change in systolic blood pressure the following days was not significant.

Table 2 shows the mean difference between average systolic/diastolic blood pressure in the different ways of measurements and different HBP schedules. Mean OBP was significantly higher than average HBP (systolic/diastolic, $3.3 / 3.8 \mathrm{mmHg}, \mathrm{p}<0.05 / \mathrm{p}<0.001$ ). Mean systolic HBP (all readings day 2-4) was significantly lower than average systolic daytime ABP $(-4.6 \mathrm{mmHg}, \mathrm{p}=<0.001)$. Mean diastolic HBP was not significantly lower when only measuring HBP for 3 days $(-1.5 \mathrm{mmHg}, \mathrm{p}=0.08)$ and just significant when measuring $\mathrm{HBP}$ for 4 days $(-1.6 \mathrm{mmHg}, \mathrm{p}=0.035)$. There was no significant difference between the different HBP schedules (three measures three times daily for four days or three measures twice daily for three days) (shown in Fig. 1).

Fig. (1) shows the Bland-Altman plots for both systolic and diastolic blood pressure to further evaluate agreement of mean values ABP versus HBP (all reading day 2-4). In these plots limits of agreement are derived from the standard deviations of the mean difference between the measurements. Visual inspection of these plots shows that there was a systematic difference especially in systolic blood pressure. The difference was present over the entire range of systolic values. The mean diastolic difference was just significant.

\section{Correlation of Blood Pressure Measurements}

Table 3 shows correlation analyses between average OBP and HBP with average daytime ABP. The highest systolic correlation coefficient was seen for the four day HBP schedule including all readings (systolic/diastolic, $r=0.69 / \mathrm{r}=0.61$, $\mathrm{p}<0.001 / \mathrm{p}<0.001)$. Systolic blood pressure readings in the clinic showed a weak correlation with daytime ABP $(r=0.52$, $\mathrm{p}<0.001)$, whereas the diastolic correlation was stronger $(\mathrm{r}=0.64, \mathrm{p}<0.001)$.

The effect of including an increasing number of measurements gives a better correlation, but as seen in Table 2 mean values the home blood pressure only decline $0.5 / 0.1$ $\mathrm{mmHg}$ (systolic/diastolic) when measured four days three times daily (average of 27 measurements) instead of three days twice daily (average of 12 measurements), and this difference was not significant.

\section{Questionnaire}

Table 4 shows the results of the questionnaire, which was fulfilled of 100 patients. It showed general acceptability of the system. Only $83 \%$ read the written instructions. None had problems getting a good signal to the monitor. All found it okay or easy to use the blood pressure device. Almost all found it easy or okay to turn on the monitor, $82 \%$ found it easy to use the monitor, whereas $18 \%$ found it okay. Only $6 \%$ missed functionality in the monitor or were bothered by the monitor, and $96 \%$ felt that the communication with the monitor was good and informative. Only $2 \%$ found it burdensome and time consuming to make three blood pressure measurements three times daily.

\section{DISCUSSION}

The study showed that telemedical HBP was lower than daytime ABP and office blood pressure. There was a better correlation between HBP and daytime ABP than for OBP and daytime ABP. Systolic HBP on day 1 was higher than on each of days 2-4, with only a slight non-significant day-today decrease in BP level from day 2-4. The study showed no significant difference between the use of three measurements

Table 1. Mean values of office (OBP), home (HBP) and ambulatory blood pressure (ABP) in 102 patients. Significance levels are shown for the comparison between the different blood pressure measurements and the daytime ABP.

\begin{tabular}{|c|c|c|}
\hline & Systolic Blood Pressure \\
$(\mathbf{m m H g})$ & $139 \pm 18 *$ & $\begin{array}{c}\text { Diastolic Blood Pressure } \\
(\mathbf{m m H g})\end{array}$ \\
\hline \hline OBP & $136 \pm 13 \pm 12 * * *$ \\
\hline Daytime, ABP & $135 \pm 15$ & $81 \pm 7$ \\
\hline HBP, day 1 & $132 \pm 15 * *$ & $80 \pm 10$ \\
\hline HBP, day 2 & $131 \pm 16 * * *$ & $79 \pm 10 *$ \\
\hline HBP, day 3 & $131 \pm 14 * * *$ & $79 \pm 10$ \\
\hline HBP, day 4 & $132 \pm 15 * * *$ & $80 \pm 10$ \\
\hline HBP, day 2-3 (morning \& evening) & $132 \pm 14 * * *$ & $79 \pm 10 *$ \\
\hline HBP, day 2-4 (all readings) & & \\
\hline
\end{tabular}

Values are expressed as means $\pm \mathrm{SD}$. Significance level: $* * * \mathrm{p}<0.001, * * \mathrm{p}<0.01,{ }^{*} \mathrm{p}<0.05$ 
Table 2. Mean difference between average systolic/diastolic blood pressure in the different ways of measuring blood pressure and different HBP schedules.

\begin{tabular}{|c|c|c|}
\hline & $\begin{array}{c}\text { Mean systolic difference } \\
\text { mmHg }[95 \% \mathrm{CI}]\end{array}$ & $\begin{array}{c}\text { Mean diastolic difference } \\
\mathrm{mmHg}[95 \% \mathrm{CI}]\end{array}$ \\
\hline $\mathrm{OBP}$ - daytime ABP & $3.3[0.2 ; 6.4] *$ & $3.8[2.1 ; 5.6]]^{* * *}$ \\
\hline HBP, day 2-3 (morning \& evening) - daytime ABP & $-4.1[-6.6 ;-1.8] * * *$ & $-1.5[-3.2 ; 0.2]$ \\
\hline $\begin{array}{c}\text { HBP, day 2-4 (all readings) } \\
\text { - daytime ABP }\end{array}$ & $-4.6[-6.6 ;-2.5] * * *$ & $-1.6[-3.2 ;-0.1] *$ \\
\hline HBP, day 2-3 (morning \& evening) - HBP, day 2-4 (all readings) & $0.4[-0.4 ; 1.2]$ & $0.1[-0.4 ; 0.6]$ \\
\hline
\end{tabular}

Values are expressed as means with $95 \%$ confidence intervals in brackets. Significance level: $* * * \mathrm{p}<0.001,{ }^{*} \mathrm{p}<0.05$
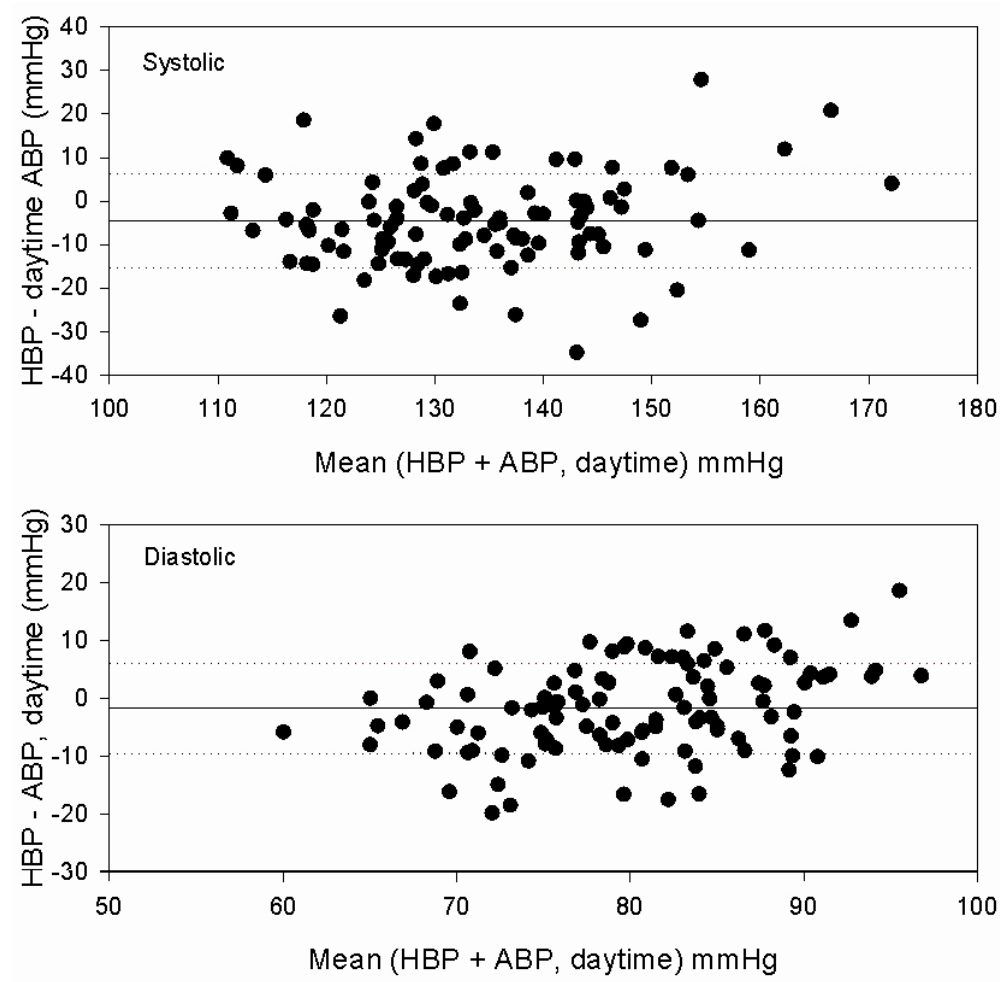

Fig. (1). Bland-Altman plots presenting differences in blood presssure between home blood pressure (HBP) and daytime ambulatory blood pressure $(\mathrm{ABP})$ for a sequential comparison. The solid black line represent the mean difference and the two dotted lines represent $\pm 2 \mathrm{SD}$.

Table 3. Correlations between average OBP and HBP on the one hand and average daytime ABP on the other.

\begin{tabular}{|c|l|c|}
\hline & Systolic BP & Diastolic BP \\
\hline OBP vs. day-time ABP & r & $0.64^{* * *}$ \\
\hline \hline HBP, day 1 vs. daytime ABP & $0.52^{* * *}$ & $0.56^{* * *}$ \\
\hline HBP, day 2 vs. daytime ABP & $0.61^{* * *}$ & $0.58^{* * *}$ \\
\hline HBP, day 3 vs. daytime ABP & $0.61^{* * *}$ & $0.56^{* * *}$ \\
\hline HBP, day 4 vs. daytime ABP & $0.63^{* * *}$ & $0.59^{* * *}$ \\
\hline HBP, day 2-3 (morning \& evening) vs. daytime ABP & $0.69^{* * *}$ & $0.55^{* * *}$ \\
\hline HBP, day 2-4 (all readings) vs. daytime ABP & $0.61 * * *$ & $0.61^{* * *}$ \\
\hline
\end{tabular}

Significance level: ***p $<0.001$ 
Table 4. Results from the questionnaire from 100 patients. Number of patients who answered each question and in brackets the percentage of the ones who answered the specific question.

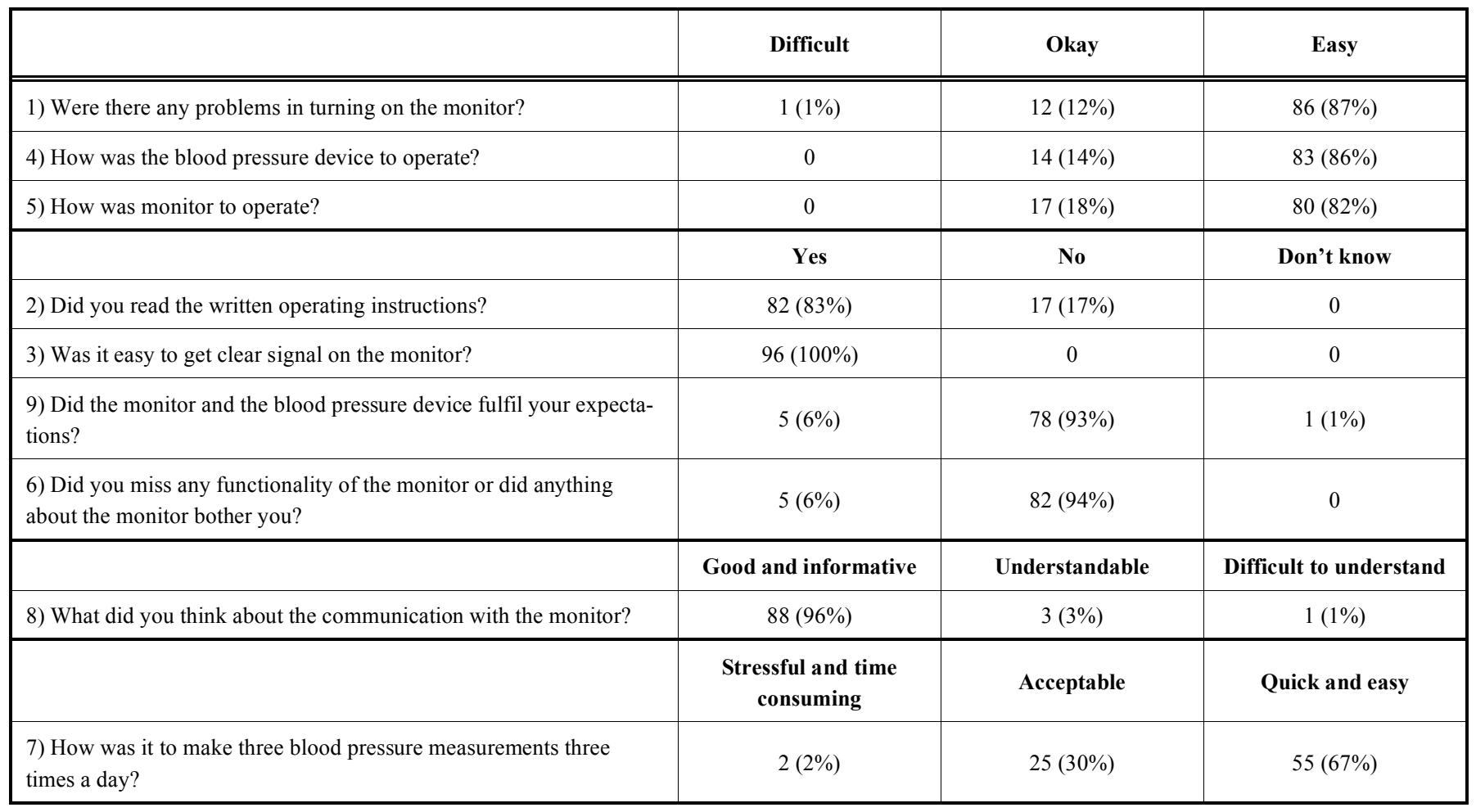

twice daily for three days (excluding day one, leaving 12 measures in the mean) and three measurements three times daily for four days (excluding day one, leaving 27 measures in the mean).

Accurate measurement of BP is essential in the diagnosis and follow-up of hypertensive patients. Several factors such as observer variation, environment, and equipment may influence BP measurements. In the present study we used automated transmission of data to eliminate self-reporting bias of HBP $[15-17,19]$ To eliminate measurement bias we used the same validated, automatic device for OBP and HBP (UA-767plusBT). Our five HBP devices were all new when starting this validation. The UA-767PlusBT is recommended for clinical use by the British Hypertension Society [20] and DablEducational $[21,22]$ achieving an A/A grade in 2 clinical studies $[23,24]$. For ABP the TM-2430 has been clinically validated $[25,26]$.

The limitations of HBP are interference with the patients' daily activities and the automated devices being inaccurate. In this study we tried to reduce the interference with patients daily activities by instructing them to measure the blood pressure in the morning before going to work (between 6 and 8 a.m.), before dinner (between 5 and 7 p.m.) and before bedtime (between 9 and 11 p.m.). To improve accuracy, we used the same automated device for the OBP and the HBP.

In our population, average systolic HBP was $4.2 \mathrm{mmHg}$ lower than the values of systolic daytime ABP. In other populations, especially among untreated young individuals, the same phenomenon has been seen [27]. This may be indicative of a reduced alertness of patients during selfmeasurement, which seems to be reflected by the decline.
The lower systolic HBP than systolic daytime ABP could also be explained by the measurement conditions. Prior to the home blood pressure measurement the patients were instructed to do the measurements in sitting position after 10 minutes of rest, and the monitor told the patient the same before the patients pressed the button of the blood pressure device. The patients may have been more compliant with regard to the period of rest than during usual measurements of blood pressure at home and certainly more relaxed than during ABP measurements, as the unexpected inflation of the cuff has been reported to be uncomfortable by many patients. In contrast, inconvenience is of minor importance when doing HBP. The last explanation could be a difference in accuracy between the blood pressure measuring devices UA-767PlusBT and the TM-2430. Both have been clinically validated according to validation guidelines. But such validations can hide an accuracy problem, especially when two devices are compared and the accepted limits in clinical validation according to the AAMI are an accuracy of $\pm 5 \mathrm{mmHg}$ with a standard deviation of $8 \mathrm{mmHg}$. Our is the first direct comparison between these two devices.

We found that the blood pressure measurements at home were significantly higher on the first day of measurements than those of the following days $[2,11,28]$. We found no significant difference between the recommended schedule and an extended schedule with three measurements three times daily for four consecutive days. Thus, according to our results measurements during three days could be recommended.

HBP by patients is associated with better blood pressure readings and improved control of hypertension compared to 
the usual blood pressure monitoring of the healthcare system [29].

HBP is presently the most acceptable method to patients and is preferred to measurements in the office or out-patient clinic [30]. The results demonstrate that the telemedical HBP system is easy to use and acceptable also to elderly people.

Our results may be influenced by a number of factors. First, we did not do "the reference standard" OBP with a mercury sphygmomanometer along with OBP measured with the UA-767PlusBT. Second, HBP was measured before $\mathrm{ABP}$, the opposite order might have yielded other results. Third, we did the HBP measurements with only one blood pressure device. It would have been interesting to compare the UA-767PlusBT with another validated HBP device to see if the lower systolic HBP was the case for other HBP devices.

Our results have several strengths. First, the study was conducted on a rather high number of patients. Second, the HBP measuring devices were new and unused. The ABP devices in our Renal Outpatients' Clinic are routinely and regularly calibrated. Third, all patients had the same instructions for the use of the devices and the importance of sitting down and relax prior to each measurements cycle was repeated by the telemedical monitor. Fourth, all blood pressure readings were sent automatically to a central server leaving no room for registration bias.

\section{CONCLUSION}

The telemedical HBP was lower than daytime ABP. The observed difference could possible be due to less pain accompanying the measurements, that the patients were more relaxed when doing the measurements or because of a systematic difference in the blood pressure device algorithms. No significant difference between the different HBP schedules, i.e. three measurements twice daily for three days and three measurements three times daily for four days. A questionnaire showed general acceptability of the system.

\section{CONFLICT OF INTEREST}

The authors confirm that this article content has no conflict of interest.

\section{ACKNOWLEDGEMENTS}

This work was supported by grants from Region Midtjylland and the Municipality of Holstebro.

\section{REFERENCES}

[1] Kearney PM, Whelton M, Reynolds K, et al. Global burden of hypertension: analysis of worldwide data. Lancet 2005; 365 : 217-23.

[2] Mancia G, Fagard R, Narkiewicz K, et al. 2013 ESH/ESC guidelines for the management of arterial hypertension: The task force for the management of arterial hypertension of the European society of hypertension (ESH) and of the European society of cardiology (ESC). Eur Heart J 2013; 34: 2159-219.

[3] Fagard RH, Cornelissen VA. Incidence of cardiovascular events in white-coat, masked and sustained hypertension versus true normotension: A meta-analysis. J Hypertens 2007; 25: 2193-8.
[4] Hansen TW, Jeppesen J, Rasmussen S, et al. Ambulatory blood pressure monitoring and risk of cardiovascular disease: A population based study. Am J Hypertens 2006; 19: 243-50.

[5] Mancia G, Bombelli M, Brambilla G, et al. Long-term prognostic value of white coat hypertension: An insight from diagnostic use of both ambulatory and home blood pressure measurements. Hypertension 2013; 62: 168-74.

[6] Bjorklund K, Lind L, Zethelius B, et al. Isolated ambulatory hypertension predicts cardiovascular morbidity in elderly men. Circulation 2003; 107: 1297-302.

[7] Stergiou GS, Siontis KC, Ioannidis JP. Home blood pressure as a cardiovascular outcome predictor: It's time to take this method seriously. Hypertension 2010; 55: 1301-3.

[8] Ward AM, Takahashi O, Stevens R, et al. Home measurement of blood pressure and cardiovascular disease: Systematic review and meta-analysis of prospective studies. J Hypertens 2012; 30: 449-56.

[9] Stergiou GS, Bliziotis IA. Home blood pressure monitoring in the diagnosis and treatment of hypertension: A systematic review. Am J Hypertens 2011; 24: 123-34.

[10] Ogedegbe G, Schoenthaler A. A systematic review of the effects of home blood pressure monitoring on medication adherence. J Clin Hypertens (Greenwich) 2006; 8: 174-80.

[11] Parati G, Stergiou GS, Asmar R, et al. European Society of Hypertension guidelines for blood pressure monitoring at home: A summary report of the second international consensus conference on home blood pressure monitoring. J Hypertens 2008; 26: 1505-26.

[12] Pickering TG, Miller NH, Ogedegbe G, et al. Call to action on use and reimbursement for home blood pressure monitoring: A joint scientific statement from the American heart association, American society of hypertension, and preventive cardiovascular nurses association. Hypertension 2008; 52: 10-29.

[13] Agarwal R, Bills JE, Hecht TJ, et al. Role of home blood pressure monitoring in overcoming therapeutic inertia and improving hypertension control: A systematic review and meta-analysis. Hypertension 2011; 57: 29-38.

[14] Myers MG. Reporting bias in self-measurement of blood pressure. Blood Press Monit 2001; 6: 181-3.

[15] Mengden T, Medina HRM, Beltran B, et al. Reliability of reporting self-measured blood pressure values by hypertensive patients. Am J Hypertens 1998; 11: 1413-7.

[16] Nordmann A, Frach B, Walker T, et al. Comparison of selfreported home blood pressure measurements with automatically stored values and ambulatory blood pressure. Blood Press 2000; 9: 200-5.

[17] Johnson KA, Partsch DJ, Rippole LL, et al. Reliability of selfreported blood pressure measurements. Arch Intern Med 1999; 159: 2689-93.

[18] Bland JM, Altman DG. Statistical methods for assessing agreement between two methods of clinical measurement. Lancet 1986; 1 : 307-10.

[19] Myers MG, Godwin M, Dawes M, et al. Conventional versus automated measurement of blood pressure in primary care patients with systolic hypertension: Randomised parallel design controlled trial. BMJ 2011; 342: d286.

[20] British Hypertension Society. Available from: http://www.bhsoc.org [Accessed 17 May 2014].

[21] Atkins N, O'Brien. The dabl educational trust device equivalence procedure. Blood Press Monit 2007; 12: 246-9.

[22] Dabl Educational Trust. Available from: http://www.dableducational.org [Accessed 17 May 2014].

[23] Verdecchia P, Angeli F, Poeta F, et al. Validation of the A\&D UA774 (UA-767Plus) device for self-measurement of blood pressure. Blood Press Monit 2004; 9: 225-9.

[24] Kobalava ZD, Kotovskaia IV, Rusakova OS, Babaeva LA. Validation of UA-767 Plus device for self measurement of blood pressure. Clin Pharmacol Ther 2003; 12: 70-2.

[25] Yip GW, So HK, Li AM, et al. Validation of A\&D TM-2430 upper-arm blood pressure monitor for ambulatory blood pressure monitoring in children and adolescents, according to the British hypertension society protocol. Blood Press Monit 2012; 17: 76-9.

[26] Palatini P, Frigo G, Bertolo O, et al. Validation of the A\&D TM2430 device for ambulatory blood pressure monitoring and evaluation of performance according to subjects' characteristics. Blood Press Monit 1998; 3: 255-60. 
[27] Stergiou GS, Nasothimiou E, Giovas P, et al. Diagnosis of hypertension in children and adolescents based on home versus ambulatory blood pressure monitoring. J Hypertens 2008; 26: 1556-62.

[28] Parati G, Stergiou GS, Asmar R, et al. European society of hypertension practice guidelines for home blood pressure monitoring. J Hum Hypertens 2010; 24: 779-85.
[29] Cappuccio FP, Kerry SM, Forbes L, et al. Blood pressure control by home monitoring: Meta-analysis of randomised trials. BMJ 2004; 329: 145.

[30] Little P, Barnett J, Barnsley L, et al. Comparison of acceptability of and preferences for different methods of measuring blood pressure in primary care. BMJ 2002; 325: 258-9.

Received: October 31, 2014

Revised: December 31, 2014

Accepted: January 01, 2015

(C) Hoffmann-Petersen and Pedersen; Licensee Bentham Open.

This is an open access article licensed under the terms of the Creative Commons Attribution Non-Commercial License (http://creativecommons.org/licenses/by-nc/3.0/) which permits unrestricted, non-commercial use, distribution and reproduction in any medium, provided the work is properly cited. 